\title{
Goal setting within family care planning: families with complex needs
}

$\mathrm{M}$ any children live in families where there is parental addiction and/or mental health problems. It is thought that $21 \%-23 \%$ of Australian children live with at least one parent with a mental illness, ${ }^{1}$ and $12 \%$ of children live with at least one parent who has a substance use problem. ${ }^{2}$ The well documented issues for these families include reduced parenting capacity, poorer family dynamics and lower child wellbeing. ${ }^{3-7}$

While there is a clear need for multifocused services and interventions, few evidence-based programs have been developed to meet the needs of all family members living with such parental problems. ${ }^{8,9}$ Family care plans, integrated within a case-management model, have the potential to provide an inclusive intervention for families with dependent children. ${ }^{10}$ Principles underlying the approach include being family centred, ${ }^{11-13}$ strength based and case-management focused. ${ }^{14}$ Care plans mobilise a family's formal and/or informal support networks, provide a means of managing sometimes fragmented and uncoordinated service responses, and enable monitoring and evaluation of treatment goals. ${ }^{14,15}$

Goal setting has been suggested as a vital element of service coordination and recovery support for people who have psychiatric disability, ${ }^{16,17}$ with important benefits to all family members. ${ }^{11}$

The goal-setting information outlined here emanated from the non-government organisation Northern Kids Care On Track Community Program. The family care planning approach was developed specifically for families with multiple problems and needs. ${ }^{18}$ To prompt goal setting, it employs 11 pre-established domains relevant to such families (Box 1). The goals formed the basis of each family member's case-management plan and were behavioural, measurable, and short- and long-term. They were reviewed by case managers every 3-4 months and, where necessary, revised in light of new challenges or goal completion.

This article reports on the goals identified by the children and parents, and the level of progress made towards these goals. It offers a service consumer's perspective, ${ }^{19}$ particularly insights into the goals and strategies employed by children. The perspectives and needs of such children have been shown to be quite different from those of parents and clinicians, ${ }^{20}$ and are important for designing future services.

\section{Method}

The data outlined here were from a retrospective review of records of families completing care plans in the program period from 2008 to 2010. Records from families who provided informed consent were reviewed in June 2011 by $\mathrm{D} \mathrm{M}$ and $\mathrm{MH}$.

\begin{abstract}
Objective: To identify the key goals that are established by children and parents from families in which parents have substance use and/or mental health problems, and the level of progress achieved towards goals over 1 year of case management.

Design, setting and participants: Participants from three rural sites of a New South Wales non-government agency completed family care plans between 2008 and 2010. They included 44 parents and 41 children from 37 families where at least one parent had a dual diagnosis or mental illness. Family care plans were analysed to identify the frequency and progress of child and parent goals across 11 domains.

Main outcome measures: Goals identified by parents and children, and change scores over a 12-month period.

Results: Children most frequently set goals to enhance their knowledge of mental illness, schooling, family connectedness and interpersonal skills. Parents most frequently set goals to improve their knowledge of mental health. Children recorded greatest goal achievement: in enhancing their mental health knowledge, community/social connectedness and accommodation needs. Parents recorded most goal progress in understanding developmental milestones of their children.
\end{abstract}

Conclusions: Goal setting appears to be an important mechanism for assisting families with complex needs. Clinicians need to address the mental health literacy of families where a parent has a substance use problem and/or mental illness.

With the support of a clinician, goals were identified by participants within the first month of being involved in the program. Goals were collaboratively negotiated between the case manager and family members.

\section{Results}

Thirty-seven families completed the goal-setting family care planning approach. Eighteen families had two parents, and 44 parents or partners set goals. Parents' psychiatric diagnosis was self-reported but verified by case managers and ranged across most types of disorders, most commonly bipolar, anxiety and/or depression. Substance use included marijuana, alcohol and/or painkillers.

Forty-one of the 93 children (aged between 8 and 18 years) set goals. The goal domains (Box 1) included goals such as "To better understand Mum's mental illness" (mental health knowledge) and "Father to spend more time with sons" (family connectedness). Case managers reviewed goals every 3-4 months; Box 2 shows the numbers of goals set and reviews undertaken for children and parents.

In addition, change scores were calculated for each of the participant's goals. When first established, goals were 


\begin{tabular}{|c|c|c|c|c|}
\hline \multirow[b]{2}{*}{ Goal domain } & \multicolumn{2}{|c|}{ Child } & \multicolumn{2}{|c|}{ Parent } \\
\hline & $\begin{array}{l}\text { No. } \\
\text { goals } \\
\text { set }\end{array}$ & $\begin{array}{c}\text { Mean } \\
\text { change } \\
\text { score }\end{array}$ & $\begin{array}{l}\text { No. } \\
\text { goals } \\
\text { set }\end{array}$ & $\begin{array}{c}\text { Mean } \\
\text { change } \\
\text { score }\end{array}$ \\
\hline Family connectedness & $78(14 \%)$ & 2.06 & $62(11 \%)$ & 1.55 \\
\hline Mental health knowledge & $79(14 \%)$ & 2.29 & $91(17 \%)$ & 2.00 \\
\hline Child development & $59(10 \%)$ & 2.00 & $36(7 \%)$ & 2.13 \\
\hline Education & $86(15 \%)$ & 2.09 & $52(10 \%)$ & 1.92 \\
\hline Interpersonal skills & $77(14 \%)$ & 1.69 & $62(11 \%)$ & 1.42 \\
\hline Substance use & $8(1 \%)$ & 2.29 & $33(6 \%)$ & 2.26 \\
\hline Lifestyle & $63(11 \%)$ & 1.98 & $49(9 \%)$ & 1.49 \\
\hline Community and social connectedness & $59(10 \%)$ & 2.13 & $54(10 \%)$ & 2.08 \\
\hline Finances & $14(2 \%)$ & 1.89 & $49(9 \%)$ & 1.60 \\
\hline Family health and wellbeing & $30(5 \%)$ & 1.44 & $30(6 \%)$ & 1.67 \\
\hline Accommodation & $11(2 \%)$ & 2.80 & $22(4 \%)$ & 2.06 \\
\hline
\end{tabular}

scored as a 0 , signifying a base level or non-achievement. At each review, families rated each goal as achieved (3), good progress (2), some progress (1) or not achieved (0). This enabled an assessment of progress for families and also allowed a calculation of change for each goal for each family member.

Overall, 564 goals were set by children. Of these, 259 were reviewed by case managers at the first review, 136 at the second and 116 at the third (Box 2). The mean change score across child goals was 2.02, indicating that, on average, children made good progress towards goals. Of the 540 parent goals, 248 goals were reviewed at the first review, 125 at the second, and 105 at the third. On average, the mean change score for goals reviewed was 1.80 for parents. On average, this indicates that most parents made just under good progress in reaching goals.

Although children set goals across all domains, the most frequent goals were around education (15\%), family connectedness (14\%), mental health knowledge (14\%) and interpersonal skills (14\%). Children showed the most change in accommodation, acquiring mental health knowledge, education about substance misuse, and improving social and community connectedness. The most frequent parent goal was improving mental health knowledge. Parents showed most change in reducing substance use and understanding child-development milestones.

\section{Discussion}

Under the family care planning approach, parents and children set a large number of goals in important life domains, and they engaged in an ongoing manner with strategies to achieve specific goals. Goal setting appears to be an important feature of a case-management approach, particularly considering that many goals were set and, on average, good progress made by families reaching their goals. In particular, children targeted and achieved goals in key areas such as education and mental health knowledge. Overall, improving mental health knowledge appears to be

\section{Number of goals set and reviewed, and mean change score}

\begin{tabular}{lllllc}
$\begin{array}{l}\text { Family } \\
\text { member }\end{array}$ & $\begin{array}{c}\text { Total no. } \\
\text { goals set }\end{array}$ & $\begin{array}{c}\text { 1st } \\
\text { review }\end{array}$ & $\begin{array}{c}\text { 2nd } \\
\text { review }\end{array}$ & $\begin{array}{c}\text { 3rd } \\
\text { review }\end{array}$ & $\begin{array}{c}\text { Mean } \\
\text { change } \\
\text { score }\end{array}$ \\
\hline Children & 564 & 259 & 136 & 116 & 2.02 \\
Parents & 540 & 248 & 125 & 105 & 1.80
\end{tabular}

an important area for clinicians to target in families with complex needs.

However, parents appeared to make less progress than children in regard to goal achievement. This could be because goals for children were less demanding or parents were more motivated to assist children in achieving their goals rather than their own. Alternatively, it could be because change is more difficult for parents than for children, due to their age, motivation, cognitive ability or current use of medication hampering goal achievement. Research should be undertaken to examine this further.

From a broader perspective, goal setting appears to be an important approach to direct and motivate parents and children where parents have psychiatric or other disabilities. The approach outlined here might also be an important method of measuring change and progress according to the goal areas that matter most to the family member. Our findings indicate that, in families with complex mental health and substance use problems, goal setting can be an important component of a family care planning approach.

Acknowledgements: We thank Northern Kids Care management, staff, parents and children. We also thank our funding bodies: the Australian Government Department of Families, Housing, Community Services and Indigenous Affairs, the lan Potter Foundation, Coffs City Rotary, NSW Health, and the Mental Health Coordinating Council.

Competing interests: No relevant disclosures.

Provenance: Not commissioned; externally peer reviewed

Received 15 Sep 2011, accepted 9 Feb 2012.

1 Maybery DJ, Reupert AE, Patrick K, et al. Prevalence of parental mental illness in Australian families. The Psychiatrist 2009; 33: 22-26. doi: 10.1192/pb.bp.107.018861.

2 US Department of Health and Human Services Substance Abuse and Mental Health Services Administration. Results from the 2008 National Survey on Drug Use and Health: National findings. Rockville MD: Office of Applied Studies, 2009. http://oas.samhsa.gov/nsduh/ 2k8nsduh/2k8Results.cfm (accessed Aug 2011).

3 Ackerson BJ. Coping with the dual demands of severe mental illness and parenting: the parents' perspective. Fam Soc 2003; 84: 109-118. http://www.familiesinsociety.org/Show.asp?docid=69 (accessed Feb 2012).

4 Mowbray C, Oyserman D, Bybee D, MacFarlane P. Parenting of mothers with a serious mental illness: differential effects of diagnosis, clinical history, and other mental health variables. Soc Work Res 2002; 26: 225 240. doi: 10.1093/swr/26.4.225.

5 Nicholson J, Biebel K, Hinden B, et al. Critical issues for parents with mental illness and their families. Rockville, MD: Center for Mental Health Services, Substance Abuse and Mental Health Services Administration, 2001. http://escholarship.umassmed.edu/cgi/ viewcontent.cgi?article=1142\&context=psych_pp (accessed Feb 2012).

6 Reupert A, Maybery D. Families affected by parental mental illness: a multiperspective account of issues and interventions. Am J Orthopsychiatry 2007; 77: 362-369.

7 Risley-Curtiss C, Stromwall LK, Truett Hunt D, Teska J. Identifying and reducing barriers to reunification for seriously mentally ill parents involved in child welfare cases. Fam Soc 2004; 85: 107-118. doi: 10.1606/1044-3894.240.

8 Fraser C, James EL, Anderson K, et al. Intervention programs for children of parents with a mental illness: a critical review. Int J Ment Health Promotion 2006; 8: 9-20. 
9 Reupert A, Maybery D. Don't forget the kids: working with families affected by parental mental illness. In: Moore E, editor. Case management for community practice. Sydney: Oxford University Press, 2009: 346-366

10 Reupert AE, Green KT, Maybery DJ. Care plans for families affected by parental mental illness. Fam Soc 2008; 89: 39-43 doi: 10.1606/10443894.3707.

11 Allan RI, Petr CG. Rethinking family-centered practice. Am J Orthopsychiatry 1998; 68: 4-15.

12 Dempsey I, Keen D. A review of processes and outcomes in familycentered services for children with a disability. Top Early Child Spec 2008; 28: 42-52. http://tec.sagepub.com/content/28/1/ 42.full.pdf+html (accessed Feb 2012).

13 Dunst CJ, Trivette CM, Hamby DW. Meta-analysis of family-centred helpgiving practices research. Ment Retard Dev Disabil Res Rev 2007; 13: 370-378.

14 Lowenstein A. A case management demonstration project for the frail elderly in Israel. Care Manag J 2000; 2: 5-14.

15 White M, Gundrum G. Case management. In: Evashwick C, editor. The continuum of long-term care: an integrated systems approach. 2nd ed. Stanford: Thompson Delmar Learning, 2001: 168-181.
16 Clarke SP, Crowe TP, Oades LG, Deane FP. Do goal-setting interventions improve the quality of goals in mental health services? Psychiatr Rehabil J 2009; 32: 292-299.

17 Victorian Department of Human Services. Standards for psychiatric disability rehabilitation and support services. Melbourne: DHS, 2004 http://www.health.vic.gov.au/mentalhealth/pdrss/pdrss_ standards.pdf (accessed Aug 2011).

18 Reupert A, Maybery D, Goodyear M. A model of care for families where parents have drug and alcohol and mental health issues. Northern Kids Care - On Track Community Programs, 2010. http:// clients.tropixel. com.au/ontrack/OnTrackFinalReport281010.pdf (accessed Aug 2011).

19 Rapp CA, Kisthardt W, Gowdy E, Hanson J. Amplifying the consumer voice: qualitative methods, empowerment, and mental health research. In: Sherman EA, Reid WJ, editors. Qualitative research in social work. New York: Columbia University Press, 1994: 381-395.

20 Reupert AE, Maybery D. "Knowledge is power": educating children about their parent's mental illness. Soc Work Health Care 2010; 49: 630-646. 
Notes

40 MJA Open I Suppl I · 16 April 2012 